\title{
GEOPROCESSAMENTO APLICADO AO DIAGNÓSTICO DE USO E COBERTURA DA TERRA NA MICROBACIA HIDROGRÁFICA DO CÓRREGO HERMES - RONDÔNIA
}

\author{
J. M. S. LINHARES ${ }^{1}$, E. SEHNEM, E. BALBINOT, R. T. G. ANDRADE e D. P. L. SILVA \\ Instituto Federal de Amazonas \\ joiada.linhares@ifam.edu.br
}

Artigo submetido em outubro/2011 e aceito em janeiro/2014

\section{RESUMO}

A microbacia hidrográfica do córrego Hermes, inserida no cone-sul de Rondônia, vem enfrentando severas implicações ambientais relacionadas às mudanças do uso da terra, tais como a conversão da floresta em áreas de lavouras e pastagens para criação extensiva de gado. Tais alterações são devidas, em um primeiro momento, à consolidação de um Programa de Integração Nacional PIN, através da implantação do projeto de Colonização Paulo Assis Ribeiro, e mais recentemente vem sendo ampliadas por uma nova dinâmica econômica ligada ao mercado de exportação de alta rentabilidade, a agroindústria. $\mathrm{O}$ objetivo deste estudo foi avaliar as causas e consequências das mudanças do uso e cobertura da terra na microbacia hidrográfica do córrego Hermes, através da aplicação de método espacial e não espacial de geoprocessamento. Os resultados analíticos de métricas de paisagem indicam que $82,76 \%$ da área correspondem a uma matriz de pastagem de gramíneas, e que $14,64 \%$ reportam-se a cobertura vegetal nativa seccionada em 18 fragmentos pouco inter-relacionados, havendo ainda 1,94\% e 0,66\% relativos à agricultura (lavoura perene e anual) e áreas edificadas, respectivamente. Depreende-se, por fim, que o intenso desflorestamento, com fins de aumento de áreas destinadas às atividades de agropecuária, é a principal causa da devastação da floresta de transição na $\mathrm{MBCH}$ RO, emanando desta outras formas de degradação ambiental, como erosão, assoreamento dos cursos de água perenes, aumento da carga de partículas em suspensão e dissolvidas, e, por fim, modificação dos ciclos hidrológicos e de carbono em escalas local, regional e global.

PALAVRAS-CHAVE: Mudanças no uso da terra, Desmatamento, Fragmentação florestal.

\section{GEOPROCESSING APLYED TO LAND COVER END USE DIAGNOSIS ON HYDROGRAPHIC MICRO BASIN'S STREAMLET HERMES NASCENT - RONDÔNIA, BRAZIL}

\begin{abstract}
The streamlet Hermes's hydrographic microbasin, inserted into the Rondonia's southern-cone - Brazil's Amazonian region - has been facing severe environmental implications related to changes in land use, such as the conversion of forest into crops and pastures for extensive cattle husbandry. Such changes are due firstly to the consolidation of a National Integration Program - PIN, through the implementation of the colonization project 'Paulo Assis Ribeiro', and more recently to a new economic dynamics, linked to a high rentable export market, the agribusiness. This study's objective was to evaluate causes and consequences of those changes in land cover and land use in the streamlet Hermes's hydrographic microbasin, through spatial and
\end{abstract}

non-spatial geoprocessing methods application Landscpae metrics analytical results indicate that $82,76 \%$ of area correspond to a matrix of pasture grasses, $14,64 \%$ relate to native vegetation sectioned into 18 fragments few interrelated, there is and $1,94 \%$ and $0,66 \%$ report to agricultural (perennial and temporary crops) and built-up areas, respectively. It finally appears that the intense deforestation, with purpose of agricultural activities areas increase, is the main cause of forest devastation, resulting from that cause other sort of environmental degradation, as erosion, silting up the perennial water ways, increasing load of suspended and dissolved particulates, and finally modification of the hydrological and carbon cycles locally, regionally and globally.

KEYWORDS: Land use changes, Deforestation, Forest fragmentation 


\section{INTRODUÇÃO}

O espaço geográfico no sul do estado de Rondônia possui processos produtivos principalmente relacionados à produção de matérias-primas e alimentos derivados de atividades agrárias. Em função das necessidades crescentes de atendimento destas demandas nos mercados interno e externo, tais atividades humanas têm proporcionado significativas mudanças quantiqualitativas no meio urbano e rural, ocasionando pressões sobre a diversidade e disponibilidade de recursos naturais, bem como alterações estruturais (estrutura fundiária original baseada na pequena propriedade rural familiar, agora empresa rural) e funcionais (produção agropecuária de subsistência para lavoura e pecuária comercial - agronegócio) na paisagem da área estudada. Para identificação e compreensão destas alterações, é importante conhecer dois momentos marcantes e distintos da economia regional no século passado - o período que vai até o final dos anos sessenta e, posteriormente, o que se estende às décadas de oitenta e noventa, quando a paisagem do sudoeste Amazônico começou a mudar intensamente.

Até o término dos anos sessenta, as principais atividades geoeconômicas na microbacia do córrego Hermes estavam assentadas no extrativismo mineral (extração aurífera decadente) e vegetal (produtos florestais) e nos sistemas tradicionais de agricultura e pecuária. Dentre estes sistemas produtivos destacavam-se a agricultura de subsistência, praticadas por nativos, afrodescendentes e migrantes nordestinos que vieram para região com propósito de trabalhar nos seringais do vale do Guaporé e afluentes, e a pecuária (bovina), realizada por meio de criação extensiva de gado, ainda incipiente nessa porção do espaço Amazônico (BECKER, et al, 1990).

No princípio dos anos setenta, com a inserção do Território Federal de Rondônia no processo de desenvolvimento do modo capitalista de produção agroexportador, novos sistemas agropecuários foram implantados na região. Isto significou uma "reconfiguração" planejada do espaço geográfico do cone-sul rondoniense e, por conseguinte, da área estudada, sendo esta marcada pela consolidação de projetos de colonização, a exemplo do assentamento integrado Paulo Assis Ribeiro.

A incorporação de Rondônia ao sistema econômico-nacional contribuiu para o crescimento exponencial da atividade agropecuária nas décadas de oitenta e noventa do século XX. Na região onde se situa a microbacia do córrego Hermes, esse crescimento apresentou peculiaridades marcantes e bem distintas daquelas praticadas em décadas anteriores, que ocorreram (naquele momento) em função da entrada de migrantes do centro-sul do Brasil. Devido ao processo ter ocorrido em áreas de terra firme, mudou-se a disposição de ocupação humana, antes baseada no extrativismo e na agricultura tradicional desenvolvidos em solos de várzea.

A modificação no sistema de produção primária ocorrido no sul do território rondoniense significou o alargamento na atividade agropecuária, que contribuiu para o crescimento da economia regional, mas ao mesmo tempo trouxe consequências ambientais até pouco tempo desconhecidas, especialmente no que concerne a prática de manejo do uso e cobertura da terra pelos colonos migrantes, em que a floresta era vista como empecilho ao desenvolvimento e à posse da terra. A substituição da floresta por espécies cultivadas trazidas de outras regiões brasileiras e a inserção de tecnologias importadas tornou-se procedimento comum, visto como sinônimo de progresso econômico-regional (SILVA 2006). 
As implicações ambientais inter-relacionadas às alterações repentinas no uso e cobertura da terra não se limitam ao córrego Hermes, mas podem ser observadas em outros bacias brasileiras. Cavichioli et al. (2003) ao estudarem o uso e ocupação de terra em propriedades rurais na microbacia do córrego Glória, região de Taquaritinga, estado de São Paulo, esclarecem que apesar de alguns proprietários adotarem técnicas de manejo eficientes nos cultivos de cana-deaçúcar, citrus e fruticultura, ainda há muito que fazer em relação às práticas conservacionistas agrícolas.

Abdala et al., (2011) ao avaliarem as diferentes categorias de uso do solo e cobertura vegetal na microbacia do rio Uberaba, utilizando técnicas de geoprocessamento e sensoriamento remoto, concluíram que atualmente parte da cobertura vegetal remanescente é caracterizada pelos seguintes tipos: mata / cerradão (galeria, topo e encostas), cerrado, campo cerrado (sujo), que juntas perfazem o equivalente a $57 \%$ da área. A vegetação natural tem sido substituída em sua maior parte por pastagens e culturas anuais. Este processo de conversão tem comprometido o volume de água em toda a microbacia, acentuando o problema de captação e abastecimento de água no município de Uberaba no período seco.

Silva e Maniesi (2005) analisaram os limites de uso e ocupação do solo da sub-bacia hidrográfica do rio Enganado - Rondônia, através da análise de vulnerabilidade à erosão. Os resultados demonstraram a necessidade de reordenações quanto ao uso e ocupação do solo em toda a rede de drenagem no rio Enganado. A manutenção do padrão atual de uso da terra pode desencadear processos de erosão e sedimentação, trazendo implicações ambientais como assoreamento dos canais de captação de água usada pelas Pequenas Centrais Hidrelétricas - PCHs em funcionamento.

A compreensão relativa às causas das mudanças do uso e cobertura da terra é complexa em qualquer bioma brasileiro, mesmo em nível de microbacia, pois envolve um elevado quantitativo de variáveis que necessitam, muitas vezes, da análise integrada de incontáveis interações geoestatísticas para se obtenção da realidade causal sobre seus efeitos ambientais, mesmo assim repletos de um alto grau de aleatoriedade. No contexto dessa discussão, o desenvolvimento da geotecnologia, usualmente denominada no meio técnico-científico de geoprocessamento e o aperfeiçoamento dos Sistemas de Informação Geográfica - SIG, têm se apresentado como uma ferramenta eficiente na identificação das implicações ambientais inerentes a alteração repentina da paisagem sul-rondoniense (CÂMARA \& MEDEIROS, 1998). Diante deste contexto, o objetivo deste estudo foi avaliar as causas e consequências das mudanças do uso e cobertura da terra na microbacia hidrográfica do córrego Hermes - Rondônia - MBCH-RO.

\section{CARACTERÍSTICAS AMBIENTAIS DA MICROBACIA DO CÓRREGO HERMES-RO}

A microbacia do córrego Hermes localiza-se no sudeste de Rondônia, precisamente no município de Colorado do Oeste (Amazônia Legal Ocidental). Sua área é de $57.068,3 \mathrm{~km}^{2}$ (5.706,83 hectares) e está delimitada pelas coordenadas geográficas 60 30' 27" e 60 20' 50" de longitude Oeste e 13 05' 54" e 13 14' 30" de latitude Sul (Figura 1). O córrego é um dos principais formadores do rio Vermelho e do Guaporé. A totalidade de sua rede de drenagem situa-se no Complexo Geológico Colorado, embasamento constituído por rochas e estruturas do mesoproterozóico, pertencente à faixa estratigráfica do Guaporé. Este se encontra capiado por 
formações sedimentares da era Mesozóica dos períodos Cretáceo e Jurássico na seção da nascente, e depósitos aluvionares da era Cenozóica, período Holocênico na região da foz (Figura 2A) (QUADROS et al, 2007).

A rede hidrográfica é constituída por um conjunto de canais com arranjos controlados pela morfoestrutura que define um padrão de drenagem "ressequente" e "exorréico", composto por 19 canais de 1 a ordem, 3 canais de $2^{\text {a }}$ ordem, e 1 canal de 3 a ordem, num total 23 canais com comprimento linear de $77,5 \mathrm{~km}$. Uma unidade hidrológica rica em nascentes, com 52,9 km/lineares de cursos de água de $1^{\text {a }}$ ordem de drenagem (STRAHLER, 1984).

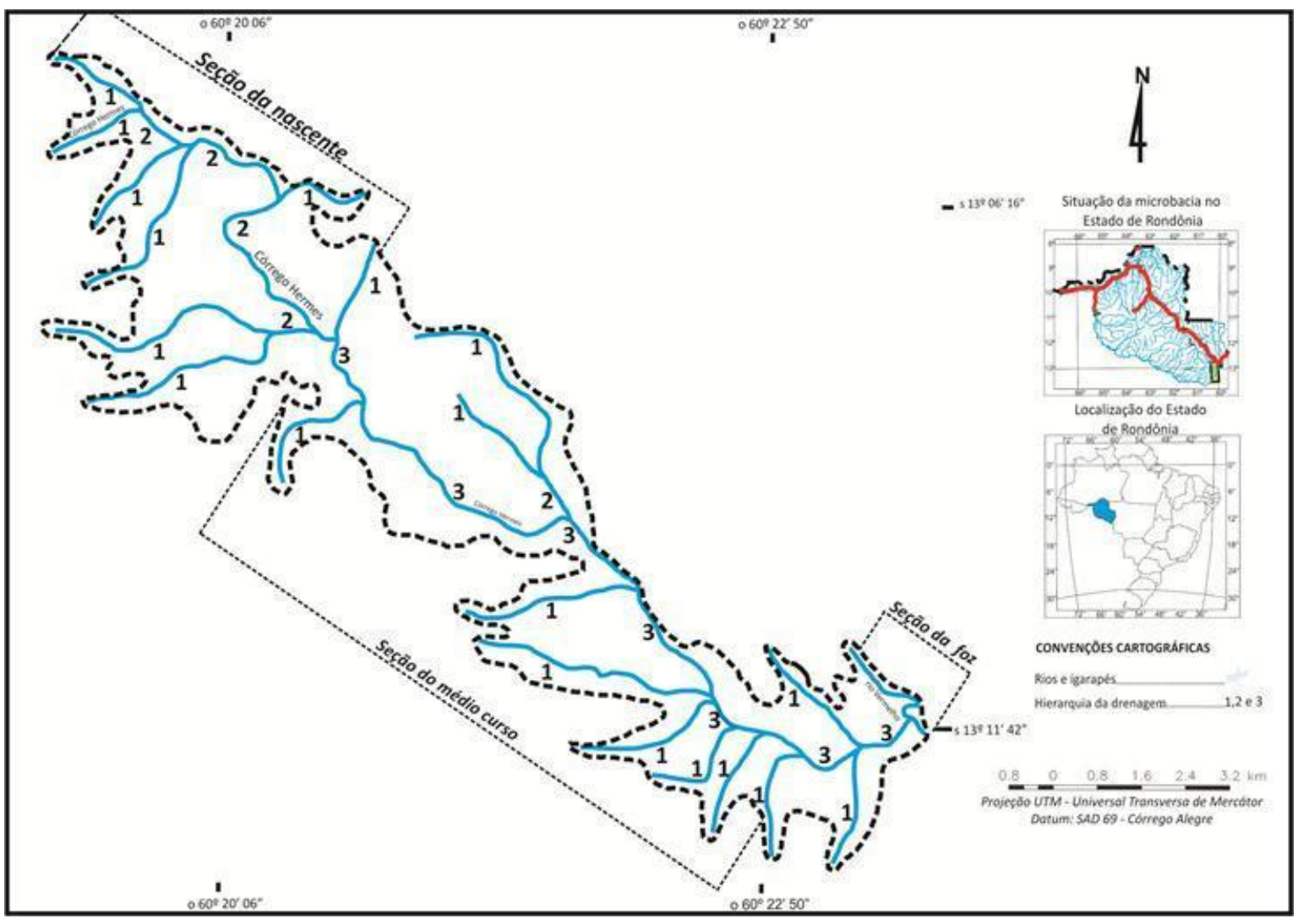

Figura 1- Localização da área de estudo e classificação hierárquica da drenagem

Foram identificadas três classes de solo: a) Argissolos Vermelho Eutróficos, correspondendo a $98 \%$ da área total; b) Gleissolos Distróficos representando $0,01 \%$ dos solos mapeados; e c) associações de Argissolos Vermelho Amarelo Eutróficos e Cambissolos, que juntos equivalem a 1,8\% dos solos da microbacia. Há presença de ambientes para desenvolvimento de Neossolos Litólicos, porém, na escala cartográfica adotada na pesquisa não foram mapeados (Figura 2B) (RONDÔNIA, 1998a). 


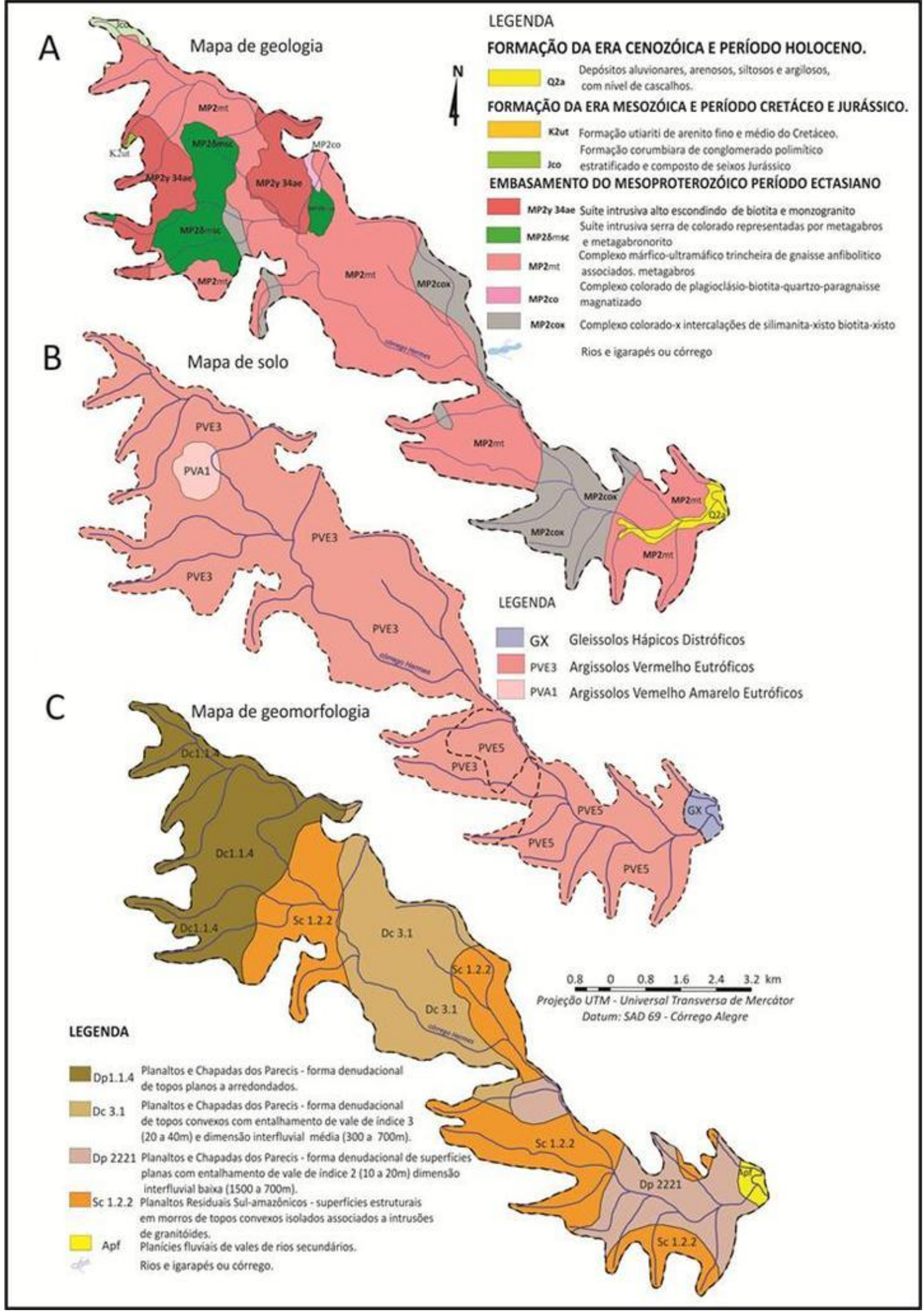

Figura 2- (A) Mapa de geologia, (B) Mapa de solo e (C) Mapa de Geomorfologia.

A geomorfologia está condicionada a estrutura geológica local, com predomínio de ambientes sedimentares, originários de processos erosivos do intemperismo de rochas do cristalino brasileiro. Assim, o relevo da microbacia foi agrupado em três conjuntos: a) planaltos e 
a Chapada dos Parecis (Dp. 1.1.4; Dc 3.1 e Dp 2221) com baixo e médio entalhamento e dimensão interfluvial, b) planaltos residuais sul - Amazônicos com superfícies estruturais e morros (Sc 1.2.2) constituídos por intrusões de granitoides e c) formas de acumulação representada por planícies fluviais (Apf) de vales de rios secundários (Figura 2C) (RONDÔNIA, 1998b; FERNANDES et al, 2001).

\section{METODOLOGIA}

Os procedimentos metodológicos foram organizados em quatro etapas: 1) Preparação da base cartográfica e processamento digital de imagens (determinação dos índices de desflorestamento dos anos de 1993, 2005 e 2009); 2) Observação do uso atual da terra; 3) Desenvolvimento da base de dados, ou seja, Banco de Dados Geográfico - BDG; e 4) Aplicação de métodos espaciais e não espaciais.

\subsection{Preparação da base cartográfica e processamento digital de imagem}

Para o registro das imagens foi preparada uma base cartográfica a partir de cartas topográficas digitais, (Divisão do Serviço Geográfico do Exército - DSG) considerando dois temas vetoriais: rede de drenagem e rodovias, na escala de 1/100.000. Posteriormente, foi selecionada uma imagem do LANDSAT 5/TM: 230/69 - Colorado do Oeste, com resolução espacial (pixel) de 30 metros. Esta foi geoprocessada através do "módulo Impima" do SPRING 5.0, com uso da composição de imagem colorida RGB (TM3 = vermelha, $\mathrm{TM} 4=$ verde e TM5 = azul) na determinação das formas e padrões espaciais de uso e cobertura da terra e banda TM4 (monocromática) na atualização e delimitação da rede hidrológica (MOREIRA, 2001).

Após georreferenciamento foi realizada pré-interpretação através do método de classificação "supervisionada" com uso do algoritmo máximo verossimilhança, em que foram consideradas três classes de uso da terra: 1) área desmatada; 2) área de floresta nativa; 3) área edificada (infraestrutura). Com base nestas informações foi confeccionado o mapa temático exploratório de uso e ocupação da terra para subsidiar o levantamento de campo (SILVA et al, 2010).

\subsection{Técnica de levantamento dos dados de uso atual da terra}

Os dados de comparação do uso atual da terra foram coletados a partir da aplicação de questionários em 21 propriedades rurais, de um total de 70 imóveis existentes na microbacia. Dois tipos de levantamentos foram empregados: i) censitário - realizado nas propriedades rurais situadas na seção de nascente da rede de drenagem correspondente aos canais de 1a à 2a ordem hierárquica; e ii) Amostragem "casual aleatória simples", nos lotes cortados pelo canal de 3a ordem do sistema de drenagem da microbacia. Também foram obtidas informações estatísticas em órgãos públicos pertinentes ao tema da pesquisa, tais como: Instituto Brasileiro de Geografia e Estatística - IBGE, Instituto Nacional de Colonização e Reforma Agrária - INCRA, Secretaria de Desenvolvimento Ambiental de Rondônia - SEDAM e Secretaria de Agricultura do Município de Colorado do Oeste - RO. 


\subsection{Aplicação do método de análise espacial e não espacial}

A aplicação do método adotado na pesquisa consistiu na integração (Modelagem Numérica de Terreno - MNT) das informações de uso atual da terra, classificação hierárquica da rede de drenagem e das características geoambientais (solo, relevo, vegetal, geologia, etc.,), através de Sistemas de Informação Geográfica - SIG/SPRING. A partir dessas variáveis foram confeccionados mapas temáticos seguindo a proposta de representação cartográfica de Martinelli (2003). Os dados não espaciais foram submetidos a tratamento estatístico no software 'Estat D+' (Figura 3) (YAMAMOTO \& ARAMINE, 1998). Ao final estes foram agrupados conforme as classes de uso da terra propostas por Sokolonski (1999).

\section{RESULTADOS E DISCUSSÃO}

A análise espacial da evolução dos índices de desmatamento revelou um acelerado processo de retirada da cobertura florestal na microbacia Córrego Hermes-RO, o que tem reduzido sua extensão geográfica. Até o ano de 1993 a MBC-RO apresentava um desflorestamento de $3.730,9$ hectares (65,55\%). No ano de 2005 houve um crescimento de 18,01\%, com aumento da área desmatada para 4.550,9 hectares. A conversão da floresta de transição em pasto e lavoura atingiu 4.760,6 hectares (aumento de 21,62\%) nos últimos 16 anos (1993 a 2009) (Figura 3).

Vários fatores geopolíticos e geoeconômicos contribuíram para a intensificação da perda da floresta nativa e da biodiversidade na área de estudo, com destaque para:

i. Incorporação do Território Federal de Rondônia na estrutura do modelo econômico nacional, como área fornecedora de matéria-prima às emergentes indústrias de bem de consumo do centro-sul do País:

ii. Consolidação de projetos de colonização oficiais desenvolvidos pelo governo Federal, que marcou o início nos anos setenta, mais precisamente em 1973, com a implantação do Projeto Integrado do Colonização Paulo Assis Ribeiro - PIC-PAR, no qual em um área de 293.580 hectares foram assentadas, em lotes de 100 hectares, 3.533 famílias, 70 dessas na microbacia do córrego Hemes - RO, em zona de expansão da frente agrícola pioneira da Amazônia Ocidental (COY, 2011). Esse padrão de colonização, induzido pelo estado brasileiro, propiciou uma migração progressiva de centenas de pequenos agricultores, principalmente das regiões Sul/Sudeste (Paraná 28,8\%, Minas Gerais 16,6\%, São Paulo 6,4\% e outros $48,2 \%$ ) e determinou a atual microrregião de Colorado do Oeste como uma área em contínuo processo de ocupação espacial até meados dos anos noventa, quando se observou o declínio nas taxas médias anuais de crescimento populacional de 1,02 (19911996) para 3,10 (1996-2000) e 1,50 (2000-2010) (IBGE, 2011a).

iii. Melhoria da infraestrutura rodoviária, com a abertura de estradas vicinais, Linhas 01, 172A (nascente), 180 e 188 (médio curso), 192 (foz) e pavimentação da rodovia RO 399, atual BR-435, bem como abertura de crédito para financiamento da atividade agropecuária, fato que favoreceu a penetração de colonos em novas áreas ainda não ocupadas. Tal processo intensificou o fluxo migratório de camponeses excluídos pelo processo de modernização agropecuária do Centro-Sul do Brasil. A migração inter-regional em pouco tempo superou a capacidade dos assentamentos oficiais, originando uma ocupação espontânea sem precedentes na foz da microbacia (SOARES-FILHO et al, 2005). 
iv. Os incentivos fiscais concedidos pelo governo às indústrias madeireiras, que associados à expansão da malha rodoviária e disponibilidade de recursos florestais, favoreceram um incremento no quantitativo de empresas pertencentes aos setores madeireiro e moveleiro (serrarias, marcenarias, dentre outras). Esse conjunto de empresas, até meados da década de noventa, apresentava maior participação no total de estabelecimentos industriais na microrregião geoeconômica da microbacia avaliada. A participação desse setor na economia do cone-sul correspondia a 35\% da arrecadação geral dos impostos do estado de Rondônia. No entanto, a partir desse período o número de empresas de beneficiamento e desdobramento mecânico da madeira bruta, e derivados em geral, voltados à carpintaria, passou a apresentar sensível redução, enquanto ocorreu aumento de empresas produtoras de lâminas de madeira, matéria-prima usada na fabricação de compensados destinados a indústria moveleira (CURI, 2000).

Embora tenha ocorrido uma notável queda percentual no crescimento populacional e na atividade econômica madeireira, esta última apontada pelo Grupo Permanente de Trabalho Interministerial como a principal causa no aumento do desmatamento na Amazônia Legal, Neste estudo observou-se a manutenção da taxa de supressão da vegetação na área da microbacia. 0 que indica que uma nova dinâmica econômica está influenciando o desflorestamento no cone-sul rondoniense (BRASIL, 2003; FEREIRA \& ALMEIDA, 2005).

Com base em observações realizadas nas propriedades rurais, foram identificadas as três principais formas de uso da terra na área estudada: a) a conversão de floresta em pastagem para criação de gado na modalidade extensiva e a derrubada e queima da floresta para cultivos anuais pela agricultura familiar (atualmente bastante incipiente); b) a retirada da floresta visando a construção de prédio para implantação de instituição pública de ensino pelo governo federal em 1993, para atender a demanda de mão de obra qualificada do mercado agroindustrial regional; e c) a instalação, em 2005 de uma indústria de beneficiamento de couro bovino. Ambas as instituições em pleno funcionamento e situadas na seção da nascente do córrego Hermes. Indiretamente, a indústria do agronegócio vem contribuindo para o aumento da perda da cobertura vegetal nativa, pois somente na microrregião de Colorado do Oeste, além da indústria citada, são encontrados seis laticínios, um frigorífico de grande porte e cinco abatedouros municipais (FIERO, 2003; MARGULIS, 2011).

A pecuária ocupa mais de $85 \%$ das terras convertidas da $\mathrm{MBCH}-\mathrm{RO}$, com cerca de 4.723,1 ha de pastagem plantada em área de floresta de transição ou tensão ecológica, e abrigava um rebanho total de aproximadamente 14.631 cabeças de bovinos. As evidências sobre a evolução do rebanho bovino no município de Colorado do Oeste, que apresentava em 1993 um efetivo de 45.000 cabeças, em 2009 totalizava 225.514 cabeças de bovinos (crescimento de 501,14\%). A análise de correlação realizada com os dados de expansão anual da área desmatada e o crescimento do rebanho bovino apresentou uma relação linear significativamente forte e positiva $\left(r^{2}=0,9347\right)$ e corroboram para a hipótese que a expansão da criação extensiva de gado é a principal causa da degradação ambiental na área avaliada (Figura 4). 


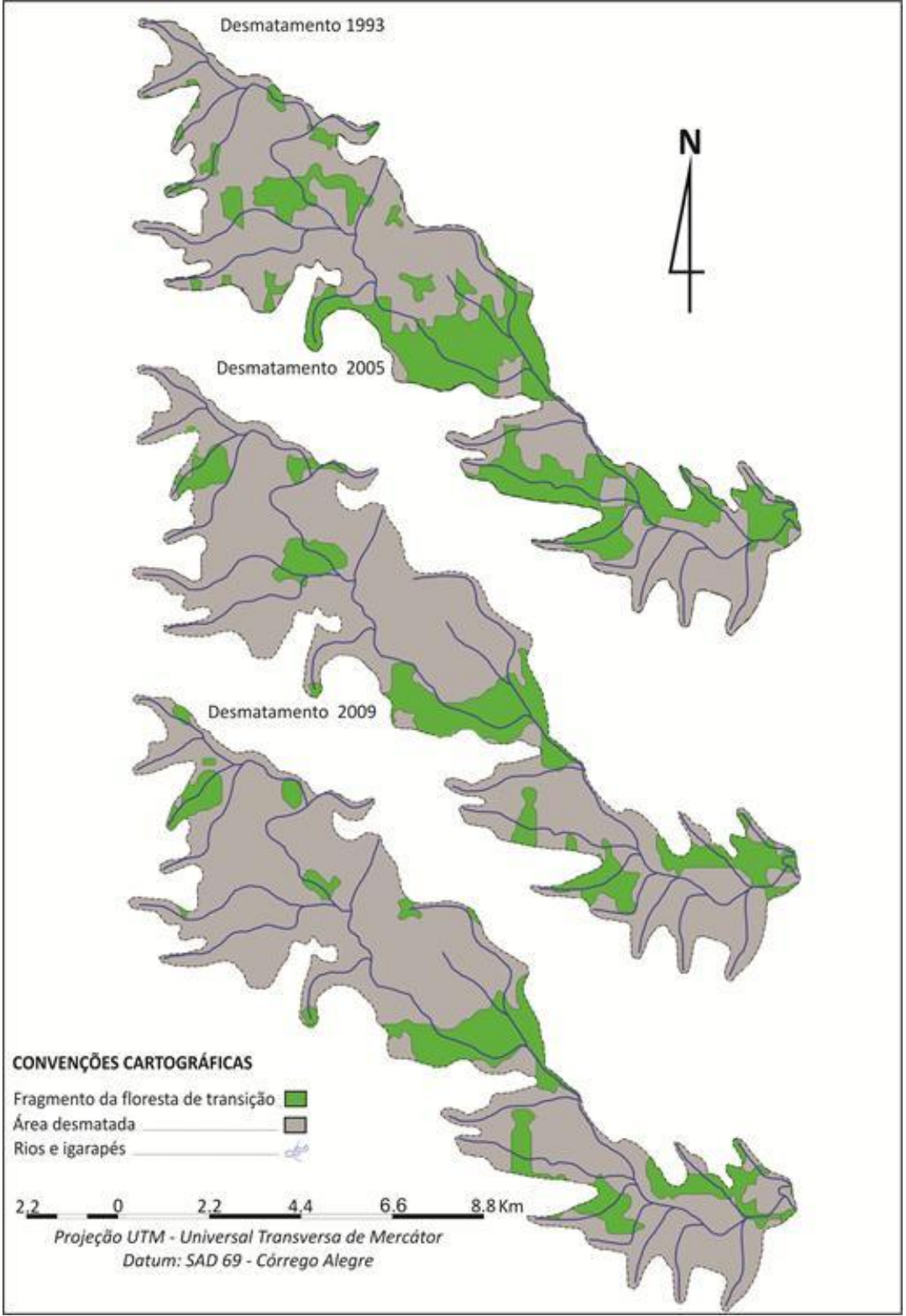

Figura 3 - Evolução da perda da cobertura da floresta de transição ou tensão ecológica entre 1993 a 2009.

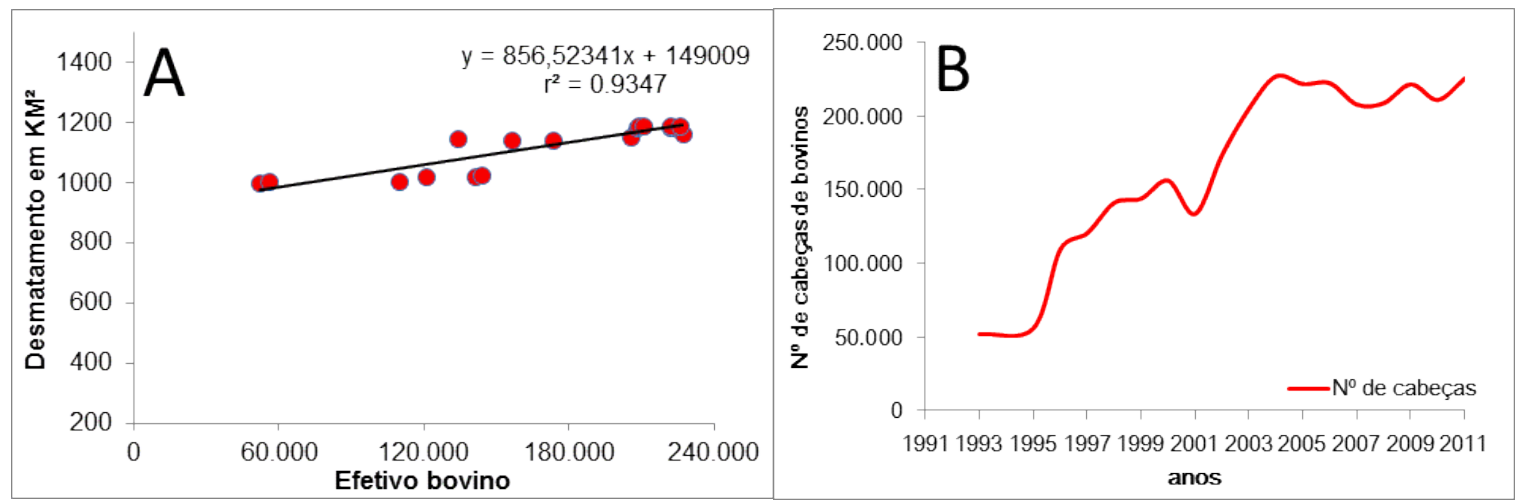

Figura 4 - (A) Correlação da expansão da área desmatada e crescimento anual do rebanho bovino entre 1993 a 2009 IBGE (2011b) INPE/PRODES (2011). (B) Evolução do rebanho bovino no município de Colorado do Oeste - RO IBGE (2011b). 
Parece ser uma fábula afirmarmos que pouco mais de setenta pequenos proprietários de imóveis rurais possam ter causado tamanha implicação ambiental na área da rede de drenagem do córrego Hermes no cone sul rondoniense, porém, Fearnside (2005) em seus ensaios teóricos sobre o desmatamento na Amazônia, esclarece que os pequenos fazendeiros, apesar de serem responsáveis por apenas 30\% do desflorestamento na bacia amazônica brasileira, responderam, dentro da área que eles ocupam, em intensidade maior que as médias e grandes fazendas, que detêm $89 \%$ da posse da terra privada na Amazônia legal.

Escada (2003) estudou a evolução dos padrões de uso da terra na região centro-norte do território rondoniense e observou que a pequena propriedade familiar apresentou maior contribuição para o aumento do desflorestamento quando comparado a grande propriedade, uma vez que a proporção de área ocupada pelos minifúndios são maiores. Esta peculiaridade advém do fato de Rondônia ter um espaço fundiário estruturado com base na pequena unidade produtiva, através dos assentamentos dirigidos criados pelo Plano de Integração Nacional, iniciado pelos militares na década de 1970. Rivero et al (2009) esclarecem a necessidade de estudos detalhados sobre a participação efetiva da pequena produção agropecuária na expansão do desmatamento. No entanto, ressaltam que a pecuária extensiva, em especial a criação de gado de corte, é uma atividade com grande presença da pequena propriedade familiar rural, pois esta funciona como poupança de renda futura. Associada a expectativa de aumento na rentabilidade, em uma visão sistêmica, esta atividade pode ter efeito ambiental muito mais amplo, no que diz respeito a perda de cobertura da vegetação na Amazônia legal.

Em uma visão geral da paisagem constatou-se que a área avaliada é composta por fragmentos remanescentes de floresta tropical de transição ou de tensão ecológica, que representa $14,64 \%$ da cobertura vegetal, isolados por uma matriz de pastagem de gramíneas (planta da família brachiaria brizantha cv. marandu) que constituem 82,76\% do total da cobertura vegetal. As demais classes de uso e cobertura da terra - agricultura (lavoura perene e anual) e áreas edificadas - representam 1,94\% e 0,66\%, respectivamente (Figura 5). Esse conjunto heterogêneo de formas naturais e artificiais atualmente é típico no topo do planalto da chapada dos Parecis no município de Colorado do Oeste - RO.

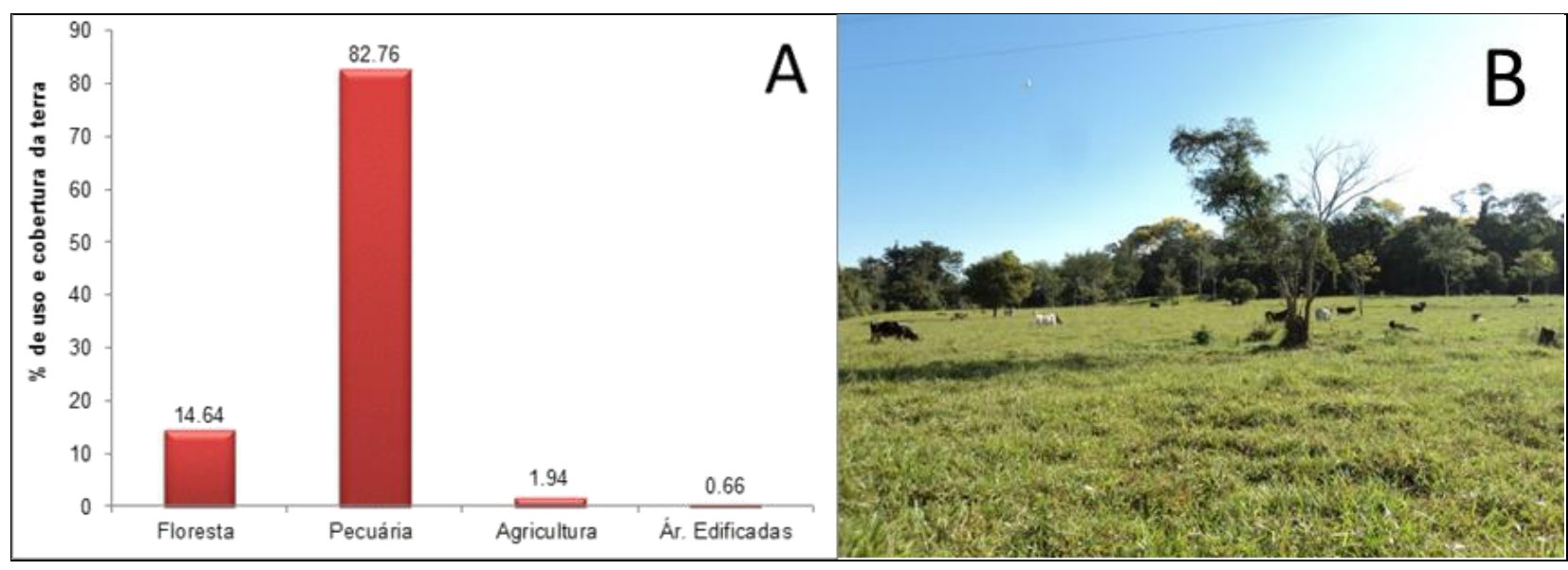

Figura 5 - (A) \% de uso e cobertura da terra; (B) paisagem da principal classe de uso da terra na microbacia Córrego Hermes-RO. Fonte: Acervo dos autores. 
As mudanças de cobertura da terra ocorridas na microbacia são de dois tipos: conversão e modificação (ESCADA, 2003). A partir do cruzamento de informações obtidas em campo com a aplicação de questionários junto aos proprietários de imóveis rurais, foi possível observar que as transformações na paisagem, em sua maioria são oriundas do processo de conversão de uma classe natural para uma classe cultivada e edificada. A chegada das primeiras famílias no assentamento PIC Paulo Assis Ribeiro, dentro da área da $\mathrm{MBCH}-\mathrm{RO}$, marcou o início da supressão da floresta nativa para dar lugar a lavoura de subsistência. Que posteriormente, devido a redução dos incentivos financeiros do governo federal no início da década de 1990, foram gradualmente substituídas por pastagens. Outro padrão de conversão observado está relacionado a substituição da floresta por áreas edificadas. Desde meados da década de oitenta foram implantadas cerca de $80 \mathrm{Km}$ de vias de acesso cortando no sentido longitudinal e vertical a microbacia. Essas foram criadas para favorecer a circulação dos colonos e o escoamento do excedente da produção agropecuária. As estradas planejadas e implantadas em pouco tempo provocaram o desflorestamento em uma faixa marginal de 500 metros, praticamente ao longo de todos os ramais ou linhas rurais e rodovias estaduais e federal, gerando atualmente um padrão espacial na fronteira agrícola do tipo consolidada, cujo uso, ocupação e as mudanças de cobertura da terra concentram-se ao longo das estradas, com predominância de pequenos, médios e esporadicamente grandes produtores rurais (GAVLAK, et al 2011). Diniz (2002) ao estabelecer as categorias de evolução de fronteira agrícola na bacia Amazônia afirma que a fase consolidada é marcada pela agricultura comercial, ou seja, o agronegócio e a presença de grandes empreendimentos agrícolas, sobretudo ligados à pecuária. A pastagem artificial predomina na paisagem e a cobertura vegetal nativa é encontrada no fundo das propriedades rurais. $O$ processo de conversão observado na área de estudo resultou na formação dos fragmentos remanescentes de floresta nativa na microbacia do Córrego Hermes - RO (Figura 6 A/B).

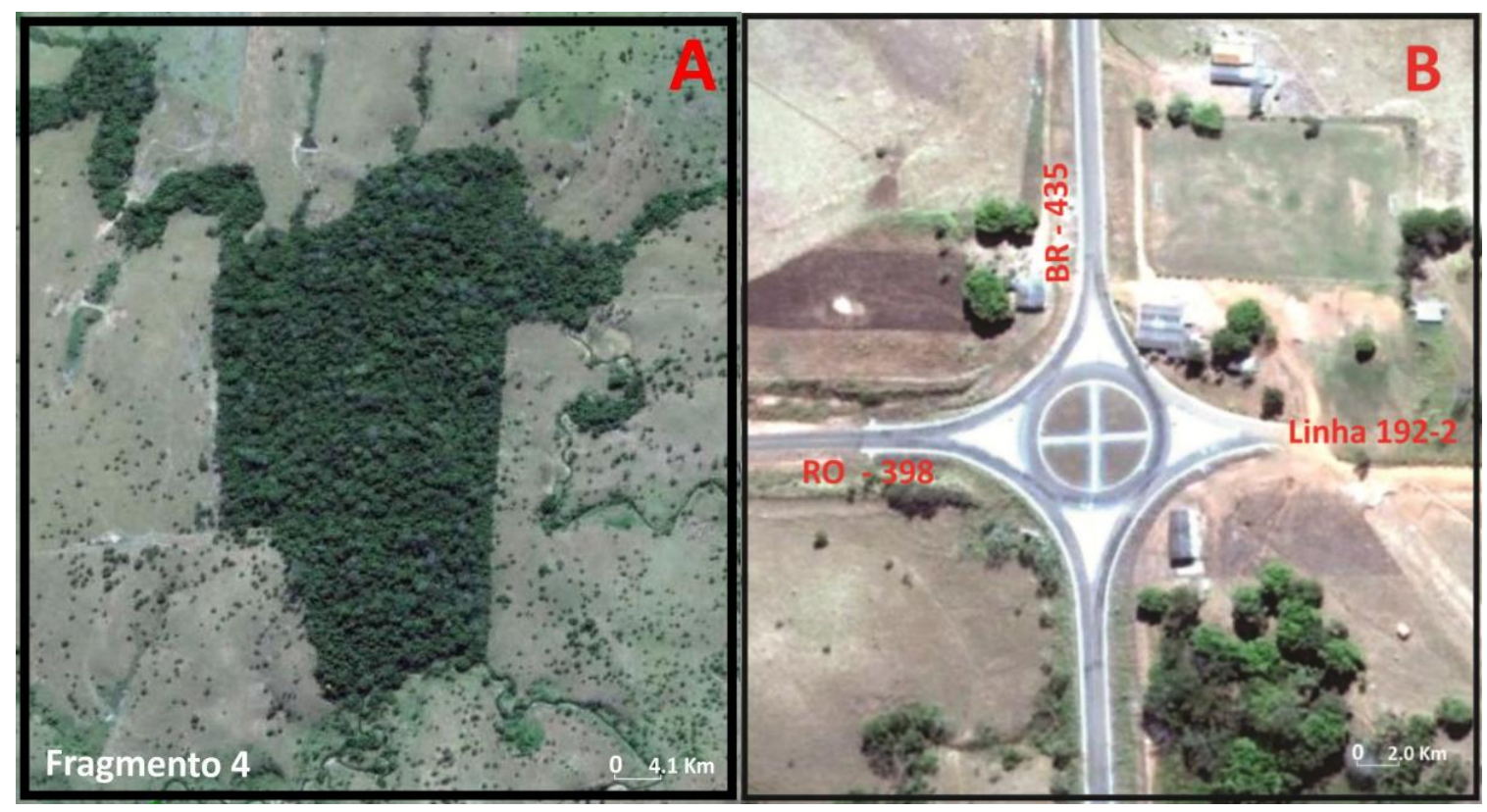

Figura 6 - (A) Fragmento florestal isolado devido ao processo de conversão da cobertura vegetal nativa em pastagem; (B) Sistema rodoviário de acesso as propriedades rurais na microbacia do Córrego Hermes - RO (Google Earth, 2013). 


\subsection{Consequência da intensificação do uso da terra na microbacia córrego Hermes - RO}

O resultado analítico de métrica de paisagem corresponde a uma área total de 5.706,83ha, onde 835,73 ha correspondem a área de 18 fragmentos remanescentes de floresta de transição ou tensão ecológica. A densidade de fragmentos em 100 ha é de 1,06 e o percentual ocupado pelo maior fragmento (404,23ha), situado no médio curso da rede de drenagem do córrego Hermes, é de $8,06 \%$. A distância média do vizinho mais próximo é de $10.508 \mathrm{~m}$, valor que demonstra uma baixíssima conectividade ou conectância entre os fragmentos (Tabela 1). Este índice revelou que a paisagem composta por cobertura vegetal nativa apresenta um alto grau de isolamento, condição que afeta o fluxo gênico, o movimento da biota entre os fragmentos florestais na MBCH-RO e a sustentabilidade de populações naturais. Gimenes e Anjos (2003) estudaram os efeitos da fragmentação sobre a comunidade de aves e reconheceram que o isolamento compromete o número de espécies não apenas em ilhas (biogeografia de ilha), mas também em fragmentos florestais continentais circundados por um habitat matriz (pastagem, agricultura permanente, campões, agroflorestal, etc.) muito diferente da vegetação florestal. Além disso, afirmam que determinados fragmentos florestais, afastados de florestas contínuas, costumam apresentar efeitos do isolamento semelhantes aos verificados em ilhas do Hawai (USA). Igualmente, METZGER (1999) faz uma análise teórica sobre a estrutura da paisagem e fragmentação e explica que o isolamento age negativamente na riqueza ao diminuir a taxa de imigração, pois as espécies que se mantém em fragmentos isolados tendem a se tornarem dominantes. Desta forma a biodiversidade do habitat diminui por extinção de espécies mais vulneráveis às condições ecológicas impostas pelo processo de fragmentação florestal.

Tabela 1- Estatística dos parâmetros métricos selecionados na análise da paisagem

\begin{tabular}{l|c}
\hline Métricas da Paisagem & Resultados \\
\hline Área total do ambiente avaliado (ha) & $5.706,83$ \\
\hline Área dos fragmentos de classes analisadas - vegetação nativa (ha) & 835,73 \\
\hline Número de fragmentos existentes da classe de vegetação & 18 \\
\hline Densidade de fragmentos em 100 ha de área da paisagem & 1.0642 \\
\hline Percentual da paisagem ocupada pelo maior fragmento (\%) & 8,065 \\
\hline Tamanho médio dos fragmentos (ha) & 46 \\
\hline Distância média do vizinho mais próximo (m) & 10.508 \\
\hline
\end{tabular}

Obs.: Elaborada a partir de Périco et al (2005).

No médio curso e foz registrou-se a redução da distância média de vizinhança entre dois fragmentos para 706m, a exemplo dos fragmentos F10, F11, F12 e F16. Estes, dependendo do grau de degradação de sua cobertura vegetal, poderão funcionar como habitat de repouso para organismos em migração à áreas de floresta contínua, principalmente do pantanal do Guaporé RO (ROSS, 2008). Entretanto, a maior densidade de estradas (rodovias estaduais e linhas ou vicinais rurais) abre a possibilidade de aumento do isolamento dos fragmentos da floresta situados nesta seção da área de estudo, pois o fluxo quase contínuo de veículos e pessoas causa isolamento ainda mais severo. Estes fenômenos foram identificados por Goosem (2007) e Laurance e Vasconcelos (2009) quando analisaram os impactos da fragmentação ocasionados pela construção de estradas que atravessavam áreas de floresta tropical existentes na África Central, Sul e Sudeste Asiático e 
América do sul, e perceberam que as estreitas clareiras lineares, abertas no interior das florestas, funcionavam como barreiras para muitas comunidades biológicas. E afirmam que algumas espécies de pássaros observados no estudo não ultrapassavam clareiras estreitas com largura inferior a 30 metros, permanecendo confinados em determinada parte da floresta fragmentada.

A existência de mata ciliar ou ripária, que consta na legislação ambiental como Área de Preservação Permanente (APP), obrigatória sua manutenção no interior das propriedades rurais e urbanas, poderia amenizar o isolamento das espécies contidas no interior dos fragmentos e, facilitar a conectividade dos organismos biológicos da mesma família entre fragmentos de diferentes dimensões no interior da área avaliada. Mas durante o trabalho de atualização das informações de ocupação, uso e cobertura da terra em campo constatou-se que a mata ripária da MBCH-RO encontra-se bastante perturbada e degradada. Em várias propriedades visitadas observou-se que a vegetação nativa foi totalmente substituída por pastagem, até às margens dos cursos de água, com a finalidade de facilitar a dessedentação do rebanho bovino. E em algumas a pastagem próximo aos cursos de água foi abandonada e em seu lugar surgiu cobertura de vegetação secundária pobre e com baixa diversidade biológica, não apresentando qualidade, largura e comprimento adequado para favorecer o fluxo de indivíduos biológicos entre os fragmentos (Figura 07).

Condição que pode ser alcançada por meio do corredor migratório, a uma área fonte suficientemente próxima e com elevada diversidade de espécies da fauna e flora local. Rohling e Silva (2010), defini os corredores como elementos essenciais ao fluxo horizontal de organismos, constituídos de uma porção de ecossistemas naturais ou seminaturais, apresentando estruturas lineares na paisagem, que se distingue do ambiente vizinho (matriz de isolamento do fragmento) e conectam pelo menos dois fragmentos anteriormente pertencentes a uma cobertura de vegetação nativa contínua. Neste aspecto Metzger (2010) enfatiza a importância da manutenção dos corredores ripários em qualquer bioma para conservação das espécies. Porém, recomenda uma largura mínima superior a $100 \mathrm{~m}$ para implantação de corredores ripários no Bioma amazônico, independentemente do grupo taxonômico, do tipo de solo e gradiente topográfico, a fim de garantir o eficiente processo de recolonização.

Com base no parâmetro acima citado e através da ferramenta mapa de distância do SIG/SPRING 5.0 procuramos reconstituir virtualmente a mata ripária considerando toda a rede de drenagem do Córrego Hermes. Foi observado que há necessidade de recuperar cerca de 74,5 Km de mata ripária, destes, $46,1 \mathrm{Km}$ no curso principal e $28.4 \mathrm{Km}$ considerando todos os canais de 1 á ordem que atravessam fragmentos na $\mathrm{MBCH}$ - RO, incluindo as nascentes. Desta forma, a reconstituição da mata ripária significaria um triplo benefício ao meio ambiente, pois favorece o fluxo de organismos da nascente (F01) à foz (F15) e a recolonização através da floresta contínua, ainda bastante preservada, que margeia o vale do rio Vermelho ao complexo do pantanal do Guaporé. Além de amenizar o efeito da fragmentação. Além disso, caso haja reflorestamento com espécies nativas, aumentaria a área de cobertura da vegetação nativa de 835.73ha (14,6\%) para 1471.59 ha (25.50\%). Neste percentual não estão incluídos alguns canais de drenagem cujas matas ripárias poderiam ser reconstituídas com base na largura estabelecida no novo Código Florestal (BRASIL, 2013), que prever para os rios entre 10 e 50m de largura uma área de preservação permanente de $50 \mathrm{~m}$, pois os mesmos não interceptam qualquer fragmento florestal avaliado na área de estudo (Figura 7). 


\subsection{DIMENSÃO DOS FRAGMENTOS FLORESTAIS NA MBCH - RO}

A arquitetura na qual foi planejado e executado o Projeto Integrado de Colonização Paulo Assis Ribeiro - PIC-PAR afetou a estrutura da paisagem e contribuiu para um intenso processo de fragmentação da floresta de transição ou tensão ecológica, pois a análise da distribuição de frequência por classe de tamanho revelou que a maior parte dos fragmentos possui dimensões inferiores a 25ha (Tabela 2). A grande maioria dos fragmentos dessa classe apresenta áreas menores que 5ha, espaço que, segundo Périco et al (2005), é insuficiente para suportar uma fauna de médio porte. Também, estudos realizados por Viana (1998) e colaboradores em fragmentos de tamanhos distintos serviram de base para ratificar a hipótese de que os fragmentos não são autossustentáveis.

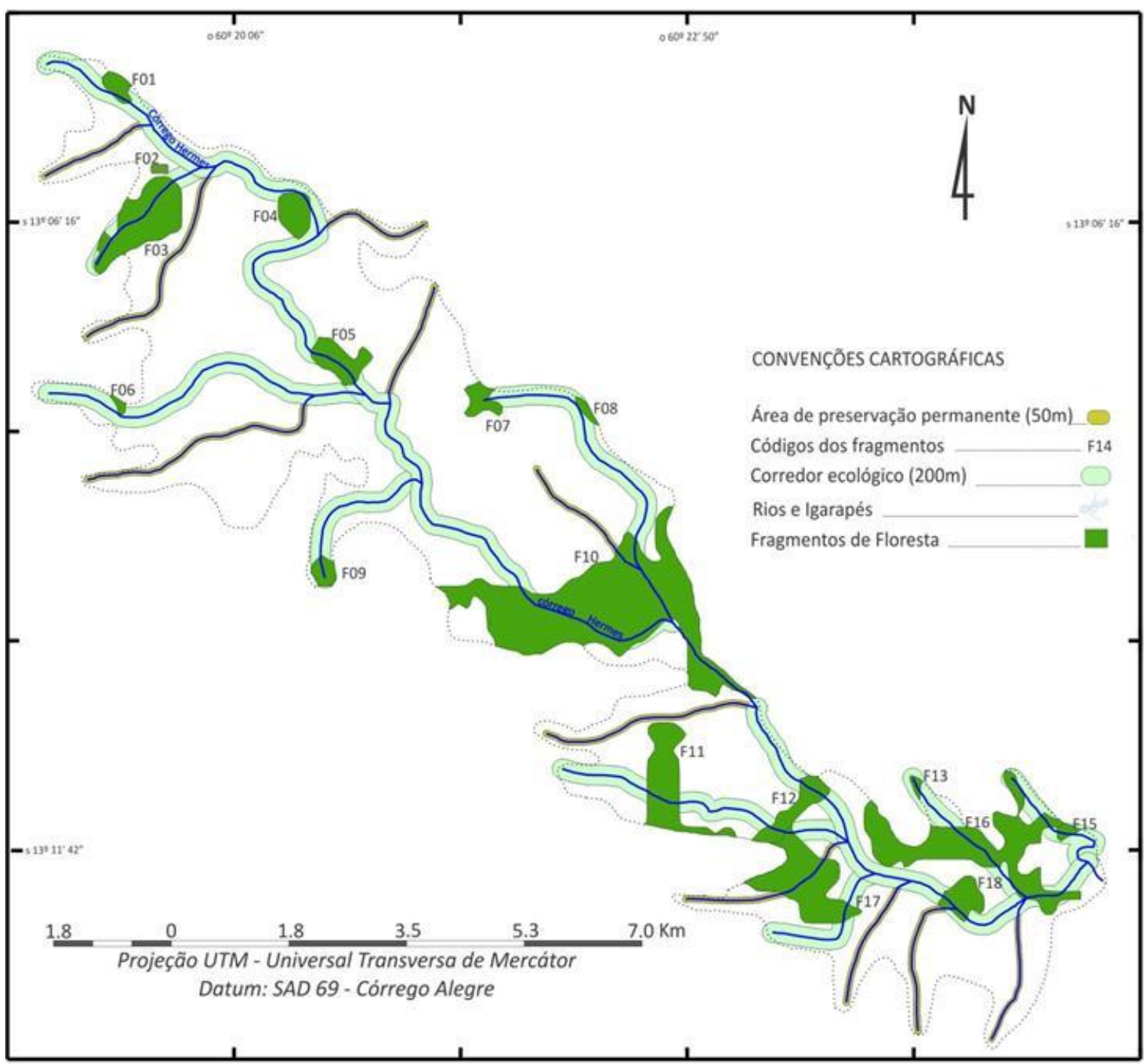

Figura 07 - Mapa de distribuição dos fragmentos e dos corredores ripários projetados para área da microbacia hidrográfica do Córrego Hermes - RO. 
Tabela 2 Distribuição de frequência dos fragmentos por classe de tamanho na microbacia do córrego Hermes Rondônia

\begin{tabular}{l|c|c}
\hline \multicolumn{1}{c|}{ Tamanho } & Número de fragmentos & Percentual \\
\hline \hline$\leq$ a 25 ha & 10 & 58,82 \\
\hline De 25 a 50 ha & 2 & 11,76 \\
\hline De 50 ha a 100 ha & 2 & 11,76 \\
\hline De 100ha e 150ha & 1 & 5,88 \\
\hline$>150$ ha & 2 & 11,76 \\
\hline Total & 17 & 100 \\
\hline
\end{tabular}

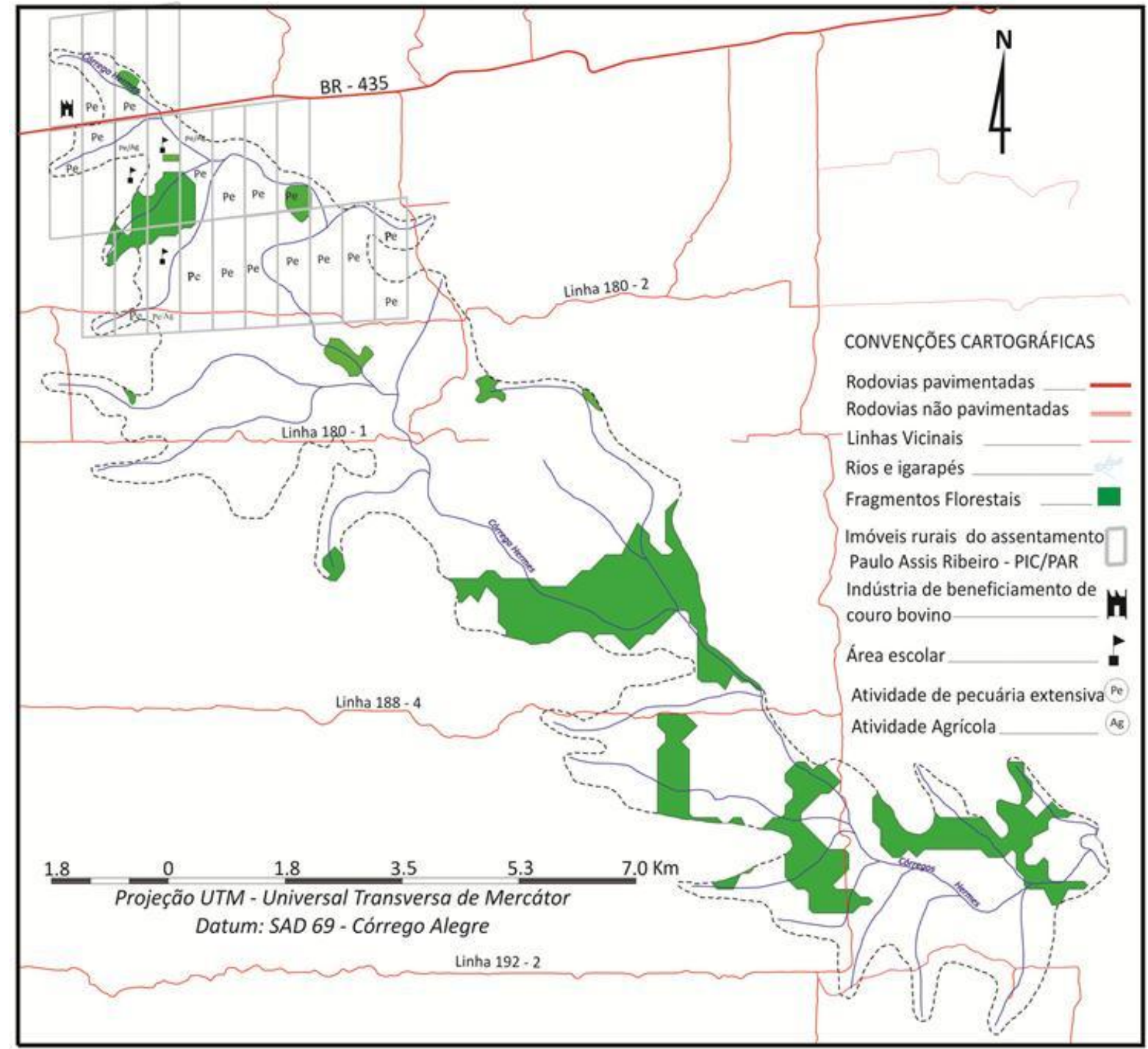

Figura 8 - Distribuição espacial de fragmentos florestais, imóveis rurais na nascente e rodovias na microbacia hidrográfica do córrego Hermes-RO.

Esta problemática ambiental não se restringe exclusivamente à área drenada pelo Córrego Hermes-RO. Atualmente o território rondoniense possui aproximadamente 136 assentamentos rurais, que em sua maioria possuem arranjos espaciais geométricos ortogonais ("espinha de peixe"), padrão que favorece maior fragmentação florestal, uma vez que os imóveis rurais são distribuídos em linhas paralelas cuja distância equivale ao comprimento máximo de duas 
propriedades rurais (Figura 8). Esse processo poderia ter sido minimizado se as instituições públicas, durante o processo de demarcação dos assentamentos, tivessem considerado as informações sobre rede de drenagem, a topografia local na criação da rede viária hierarquizada e a instituição, nos imóveis rurais privados, de reservas florestais comuns, a exemplo do modelo adotado pelo INCRA, em parte dos projetos de colonização Vale do Anari e Machadinho em 1982 (BATISTELLA e MORAN, 2005).

\section{CONCLUSÃO}

A microbacia hidrográfica do córrego Hermes - RO apresenta um padrão de uso e cobertura da terra composto por múltiplos ambientes (agrícola, pastagem, áreas edificadas e reservas florestais), definidos pela heterogeneidade de sua comunidade e desenvolvimento capitalista recente. Nesse aspecto, esta unidade hidrográfica de análise pode ser vista como um espaço geográfico compartimentado e organizado de acordo com seus agentes de ocupação. A partir da análise, os parâmetros avaliados apontam para algumas conclusões.

O intenso desflorestamento, com fins de aumento de áreas destinadas às atividades de agropecuária, é a principal causa da devastação da floresta de transição na $\mathrm{MBCH}-\mathrm{RO}$, pois provêm dessa outras formas de degradação ambiental, como erosão, assoreamento dos cursos de água perenes, aumento da carga de partículas em suspensão e dissolvidas, e, por fim, modificação do ciclo hidrológico e de carbono em escalas local, regional e global.

O histórico processo de ocupação via colonização oficial, a abertura e a pavimentação de estradas (Rodovia RO 399, transformada em rodovia federal BR-435, linhas ou estradas rurais L 172-A, 180-2,188-4 e 192-2) e os incentivos fiscais à instalação de indústrias madeireiras desencadearam uma intensa migração de colonos de outras regiões do país para o sudeste rondoniense. Estes, para garantir a posse da terra e seguindo a orientação do estado através da instituição responsável pelo assentamento Paulo Assis Ribeiro, tiveram que converter parte da floresta nativa em áreas agrícolas e pastagens, prática que tem consequências profundas na perda do patrimônio genético de vários ecossistemas do ecótono de transição entre os biomas de cerrado e floresta ombrófila Amazônica.

A organização espacial (disposição arquitetônica) dos imóveis rurais, que se situa parcialmente ou totalmente na $\mathrm{MBCH}-\mathrm{RO}$, contribui para a fragmentação florestal, o isolamento de fauna e flora, por consequência do decréscimo da diversidade biológica, e a perda de espécies por extinção. Em função desse cenário, o comprometimento de toda a sociedade, sobretudo do poder público (local, regional e nacional), passa a ser fundamental, pois a degradação ambiental em curso ameaça a sobrevivência física direta da população local e, indiretamente, de outros habitantes que necessitam dos recursos naturais existentes na floresta de transição, ou de tensão ecológica, sul-rondoniense.

\section{AGRADECIMENTOS}

Aos grupos de pesquisa Gestão agroambiental da Amazônia Ocidental, do Instituto Federal de Educação, Ciência e Tecnologia de Rondônia/IFRO e do Laboratório de Biogeoquímica Ambiental Wolfgang C. Pfeiffer, da Universidade Federal de Rondônia, especialmente aos 
pesquisadores que participaram do projeto de pesquisa. E às instituições que financiaram este estudo: Instituto Federal de Educação Ciência e Tecnologia de Rondônia - IFRO e Conselho Nacional de Desenvolvimento científico e Tecnológico - CNPq / DAMBCH-RO (Processo 109193/2011-3).

\section{REFERÊNCIAS}

1. ABDALA, V. L.; NISHIYMA, L.; TORRES, J. L.R. Uso do solo e cobertura vegetal na bacia do alto curso do rio Uberaba, Triângulo Mineiro, sudeste do Brasil. Caminhos da geografia, v.12, n.37 p. $258-267,2011$.

2. BATISTELLA, M.; MORAN, E. F. Dimensões humanas do uso e cobertura das terras na Amazônia: uma contribuição do LBA. Acta Amazônia, v 35 n.2 p. 239-247. 2005.

3. BECKER, B. K. MIRANDA, M. H. P.; MACHADO, L. O. Fronteira Amazônica: Questão Sobre a Gestão do Território. Rio de Janeiro: UNB, 1990.

4. BRASIL, Presidência da República Casa Civil, Grupo Permanente de Trabalho Interministerial para a Redução dos Índices de Desmatamento da Amazônia Legal. Plano de Ação para a Prevenção e Controle do Desmatamento na Amazônia Legal. Brasília, 2003.

5. BRASIL. Lei $\mathrm{n} 012.651$, de 25 de maio de 2012. Dispõe sobre a proteção da vegetação nativa, altera e revoga Leis e dá outras providências. Disponível em: <https://www.planalto.gov.br/ccivil_03/_Ato2011-2014/2012/Lei/L12651.htm>. Acesso em: 02/05/2013.

6. CÂMARA, G.; MEDEIROS, J. S. Geoprocessamento para projetos ambientais. 2a Ed. São José dos Campos-SP: INPE, 1998.

7. COY, M. Desenvolvimento regional na periferia amazônica: organização do espaço, conflitos de interesses e programas de planejamento dentro de uma região de ponteira o caso de Rondônia. Belém: 1983. Disponível em: <http://horizon.documen tation.ird.fr/exldoc/pleins_textes/pleins_textes_7/b_fdi_03_01/37780.pdf>. Acesso em: 29 ago. 2011.

8. CURI, W. J. Estudo para fortalecimento do setor madeireiro. Porto Velho: FIERO/SEBRAE, 2000. 164p.

9. DINIZ, A. M. A. Migração e Evolução da Fronteira Agrícola. In: XIII Encontro da Associação Brasileira de Estudos Populacionais. Ouro Preto. Anais... Minas Gerais, 2002, p. 1 - 26.

10. FIERO - Federação das Indústrias do Estado de Rondônia. Perfil socioeconômico e industrial do estado de Rondônia. Porto Velho: SENAI, 2003.

11. FERnANDES, L. C.; GUIMARÃES, S. C. P. (Coord.). Atlas Geoambiental de Rondônia. Porto Velho: SEDAM, 2001.

12. FEARNSIDE, P. M. Desmatamento na Amazônia: histórico, índice e consequências. Megadiversidade. V.1, no 1, p. 113-123, 2005.

13. FERREIRA, L. V; ALMEIDA, S.; VENTICINQUE, E. O desmatamento na Amazônia e a importância das áreas protegidas. Estudos Avançados. v. 19. no 53. p. 157- 166. 2005.

14. GIMENES, M. R.; ANJOS, L. dos. Efeitos da fragmentação florestal sobre as comunidades de aves. Acta Scientiarum. Biológica Sciences. V. 25, no 2, p. 391-402, 2003. 
15. GOOGLE EARTH. Mapa. Disponível em <https://maps.google.com.br/>. Acesso em 19/04/2013.

16. GOOSEM, M. Fragmentation impacts caused by roads through rainforests. Current Science, Vol. 993, no 11, 2007. p. 1587-1595.

17. IBGE- Instituto Brasileiro de Geografia e Estatística. Censos demográficos. Rio de Janeiro-RJ. Disponível em: <http://www.ibge.gov.br>. Acesso em: 3 set. 2011a.

18. IBGE- Instituto Brasileiro de Geografia e Estatística. Censos agropecuários. Rio de Janeiro-RJ. Disponível em: <http://www.ibge.gov.br>. Acesso em: 3 abr. 2011b.

19. INPE INSTITUTO NACIONAL DE PESQUISAS ESPACIAIS Projeto de desmatamento: Banco de Dados. 2000/2009. Disponível em: <http://www.obt.inpe.br/prodes/ index.html>. Acesso em: 5 abr. de 2011.

20. LAURANCE, W. F.; VASCONCELOS, H. L. Consequências ecológicas da fragmentação florestal na Amazônia. Oecologia Brasiliensis. 13 (3) 434-451, 2009.

21. MARGULIS, S. Causas do desmatamento da Amazônia brasileira. Brasília-DF: 2003. Disponível em: $\quad$ http://www.amazonia.org/AmazonForest/Deforestation/Margulis e WorldBank0703.pdf>. Acesso em: 13 jul. 2011.

22. MARTINELLI, M. Mapas da geografia e cartografia temática. São Paulo: Contexto, 2003. 111 p.

23. METZGER, J. P. Estrutura da paisagem e fragmentação: Análise Bibliográfica. Anais da Academia Brasileira de Ciências, 71 (3-1): 445-461, 1999.

24. MOREIRA, M. A. Fundamentos do sensoriamento remoto: e metodologias de aplicação. São José dos Campos: INPE, 2001. 250p.

25. PÉRICO, E.; CEMIN, G.; LIMA, D. F. B.; REMPEL, C. Efeitos da fragmentação de habitats sobre comunidades animais: utilização de sistemas de informação geográfica e de métricas de paisagem para seleção de áreas adequadas a testes. In: XII Simpósio Brasileiro de Sensoriamento remoto, 12, 2005, Goiânia. Anais... Goiânia, UFG, 2005.p. 2339-2346.

26. QUADROS, M. L. E. S.; RIZZOTTO, G. J. Geologia e recursos minerais do estado de Rondônia. Porto Velho-RO: CPRM, 2007. 1 CD-ROM. 153p.

27. RONDÔNIA, Secretaria de Estado do Planejamento e Coordenação Geral. Diagnóstico Sócioeconômico-Ecológico do Estado de Rondônia e Assistência Técnica para Formulação da Segunda Aproximação do Zoneamento-Sócio-Econômico-Ecológico. (Relatório Técnico de Solos, v. 5). Porto Velho: PLANAFLORO 1998a.141p.

28. RONDÔNIA, Secretaria de Estado do Planejamento e Coordenação Geral. Diagnóstico Sócioeconômico-Ecológico do Estado de Rondônia e Assistência Técnica para Formulação da Segunda Aproximação do Zoneamento-Sócio-Econômico-Ecológico. (Relatório Técnico de Geomorfologia , v. 2, anexo A, parte 2). Porto Velho: PLANAFLORO 1998b.141p.

29. SILVA, J. M.; LINHARES, D. P.; BASTOS, W. R. Geoprocessamento aplicado a análise do uso da terra e qualidade de água na microbacia do rio Preto - Rondônia. Caminhos da geografia, $v$ 11, n. 34. p. $1-21,2010$.

30. SILVA, L. P.; MANIESI, V. Avaliação dos limites se uso e ocupação e as pequenas centrais 
hidrelétricas da sub-bacia do rio enganado - Rondônia: uma proposta de uso sustentável. Geociências, v. revista 24, n. 3, p. 267-276, 2005.

31. SOARES-FILHO, B. S.; NEPSTAD, D. C.; GARCIA, R. C.; RAMOS, C. A.; VOLL, E.; MCDONALD, A.; LEFEBVRE, P. S.; MCGRATH, D. Cenário de desmatamento para a Amazônia. Estudos Avançados, v 19, n. 54 p. 137-152, 2005.

32. SOKOLONSKI, H. H. (coord.). Manual técnico de uso da terra. Rio de Janeiro: IBGE, 1999.

33. STRAHLER, A. N. Geografia Física. 7 ed. Barcelona, Espanha: Ômega, 1984.

34. VIANA, V. M.; PINHEIRO, L. A. v. Conservação da biodiversidade em fragmentos florestais. Série técnica IPEF. v 12, n. 32, p. 25-42. 1998.

35. YAMAMOTO, K. R; AKAMINE, C. T. Estudos dirigidos de estatística descritiva. São Paulo: Érica, 1998. 280p.

36. ESCADA, M. I. S. Evolução de padrões da terra na região centro norte de Rondônia. Tese de Doutorado (Sensoriamento Remoto) - Instituto Nacional de Pesquisas Espaciais. São José dos Campos, 2003, 264p.

37. GAVLAK, A. A.; ESCADA, M. I. S.; MONTEIRO, A. M. V. Dinâmica de padrões de mudança de uso e cobertura da terra na região do distrito florestal sustentável da BR - 163. In: XV Simpósio Brasileiro de Sensoriamento remoto, 12, 2011, Curitiba. Anais... Curitiba, UFP, 2011.p. 6152-6160.

38. METZGER, J. P. O código florestal tem base científica? Natureza \& Conservação, 8 (1) 1-5, 2010.

39. ROHLING, F. J.; SILVA, N. M.; Padrão de fragmentação da vegetação nativa na zona rural associada ao perímetro urbano de Rondonópolis, Mato Grasso. Caminhos da Geografia, v 13, n. 41. p. 42-51, 2010.

40. RIVERO, S.; ALMEIDA, O.; ÁVILA, S.; OLIVEIRA, W. Pecuária e desmatamento uma análise das principais causas diretas do desmatamento na Amazônia. Nova economia. v. 19 (1) 41-66. 2009

41. SILVA, J. M. Análise integrada de qualidade de água em microbacia hidrográfica. Dissertação de Mestrado (Desenvolvimento Regional) - Universidade Federal de Rondônia. Porto Velho, 2006, 217p.

42. ROSS, J. L S. Os fundamentos da Geografia da Natureza. In: ROSS, J. L S. (Org.) Geografia do Brasil. São Paulo: Editora da Universidade de São Paulo, 2008. 